\title{
Seasonal Variation of Vitamin D via Several Parameters in Adolescents
}

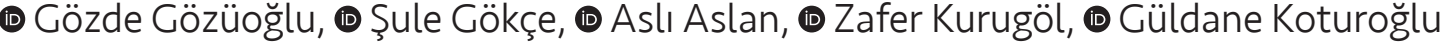

Ege University Faculty of Medicine, Department of Pediatrics, General Pediatrics Unit, İzmir, Turkey

\begin{abstract}
Aim: Vitamin D in adolescents reveals that subclinical vitamin D deficiency is continuously increasing worldwide. The aim of this study was to investigate the prevalence of vitamin D and subclinical vitamin D deficiency and risk factors among adolescents in the summer and winter seasons in İzmir.

Materials and Methods: The medical records of 90 adolescents were reviewed regarding their vitamin $\mathrm{D}$ status in the summer and winter seasons. Blood samples were obtained from 90 adolescents at the end of summer and the end of winter. These samples were assessed for calcium (Ca++), phosphorus, magnesium (Mg), parathyroid hormone, alkaline phosphatase and 25-hydroxyvitamin D concentrations. The subjects were divided into two groups; the first group consisted of the patients who were assessed for vitamin D levels and the other laboratory measurements at the end of winter $(n=46)$, the second group consisted of the patients who were assessed for the same laboratory features at the end of summer $(n=44)$. The two groups were compared in terms of demographic, clinical and laboratory characteristics.

Results: Among the 90 patients enrolled in the study, $41(45.5 \%)$ were males and $49(54.5 \%)$ were females. The median age was $11 \pm 4$ years. Vitamin D deficiency percentages of the study group for the end of the winter period was $60.8 \%$ and for the end of the summer period was $6.8 \%$ but this was not statistically significant. Vitamin D insufficiency percentages of the winter group were higher than the summer group $(93.2 \%$ vs. $39.2 \%$, $p>0.05)$. There were no differences between the groups in terms of laboratory findings concerning $\mathrm{Ca}, \mathrm{Mg}$ and the other bone parameters.

Conclusion: Contrary to the expected, we did not detect a seasonal difference in vitamin D levels in adolescents. Although laboratory findings were not found to be statistically significant in terms of vitamin D levels, we can state that the level of vitamin D in the winter season might be lower than the summer season. Therefore, it should be kept in mind that vitamin D insufficiency is more frequent at the end of the winter season and seasonal differences in the adolescent population should be considered during measurement.

Keywords: Vitamin D, seasonal variation, adolescents
\end{abstract}

\section{Introduction}

Vitamin D plays a role in the growth of bone and bone mineralization. The bone developments during adolescence accelerate in a short period of time. This increased metabolic demand suggests an increased need for calcium (Ca) and vitamin D. Low vitamin $\mathrm{D}$ and $\mathrm{Ca}$ intake, together with dark skin pigmentation and lack of sunlight exposure may predispose this age-group to nutritional rickets. Vitamin $D$ plays not only an essential role in maintaining healthy bone growth but also in reducing the risk of chronic diseases such as autoimmune diseases, malignancies, cardiovascular and infectious diseases (1). Vitamin D deficiency is a common entity in children and adolescents who are dark skinned and on vegetarian or unusual diets. The usage of anticonvulsant or antiretroviral medications, malabsorptive conditions, residence at higher latitudes, the winter season and other causes of low sun exposure are also associated with Vitamin D deficiency (2-4). Standards for defining vitamin D status in healthy children and adolescents are based on the 2016 
Global Consensus recommendations and upon serum concentrations of 25-hydroxyvitamin D (25-OHD): Vitamin D sufficiency is defined as 20 to $100 \mathrm{ng} / \mathrm{mL}$ (50 to $250 \mathrm{nmol} / \mathrm{L}$ ), Vitamin D insufficiency is defined as 12 to $20 \mathrm{ng} / \mathrm{mL}$ (30 to $50 \mathrm{nmol} / \mathrm{L})$, and Vitamin $D$ deficiency is defined as $<12 \mathrm{ng} /$ $\mathrm{mL}(<30 \mathrm{nmol} / \mathrm{L})(5,6)$. Due to the fact that the prevalence of vitamin $D$ deficiency or insufficiency might be changeable with respect to different countries, subpopulations, different ethnic and socio-economic features, the exact prevalence is not clear. However, reports have stated that the overall prevalence of vitamin $D$ deficiency in the pediatric age range is about 15 percent $(4,7,8)$.

Studies regarding vitamin $D$ in adolescents have revealed that subclinical vitamin D deficiency is continuously increasing worldwide. Many factors appear to be important in this pathogenesis such as obesity, living in temperate climates, lack of sunlight exposure, darkly pigmented skin and also social and religious customs that prevent sunlight exposure. However, even in sunshine rich countries, vitamin D deficiency can develop. Manios et al. (9) reported that sub-populations at highest risk are girls in urban/semi-urban areas during the spring months, thus indicating the need for effective initiatives to support adequate vitamin $D$ levels in these population groups.

Subclinical vitamin D deficiency (Vitamin D insufficiency) is characterized by an inadequate vitamin D level with nonspecific clinical symptoms. Because these cases are either under diagnosed or missed, subclinical vitamin $D$ deficiency is one of the most common undiagnosed medical conditions in the world (10).

The diagnosis of vitamin D deficiency is based on a combination of clinical features (which may include bone pain and tenderness, carpopedal spasms, diffuse limb pains, deformities of the lower limbs and generalized weakness, fractures, etc.), laboratory results, and radiologic findings. Those patients with nutritional osteomalacia have a very low serum 25-OHD [ $<10 \mathrm{ng} / \mathrm{mL}(25 \mathrm{nmol} / \mathrm{L})$ ], low to low-normal serum $\mathrm{Ca}$ and phosphate, and high parathyroid hormone (PTH) and alkaline phosphatase (ALP) (both total and bonespecific) levels. Radiographic evidence shows a widening of the growth plate with impaired mineralization.

The studies have reported that the risk of vitamin $D$ deficiency could be related to many risk factors. The current study aimed to investigate the frequency of vitamin $D$ insufficiency and vitamin D deficiency and the risk factors among adolescents in the summer and winter seasons in Izmir, which is located in the west of Turkey and is a sunshine rich city.

\section{Materials and Methods}

\section{Study Group}

We evaluated 90 adolescents (aged between 10-18 years) who presented for various reasons at the outpatient clinic of Ege University Children's Hospital between July and September 2011 and between January and March in 2012. Those patients with chronic illness or use of medications known of affect bone metabolism were excluded. The protocol for the study was approved by the Ethical Committee and informed consent was obtained from the parents or guardians of all eligible children.

The subjects were divided into two groups; the first group consisted of those patients who were assessed for vitamin $D$ levels and the other laboratory measurements at the end of winter, the second group consisted of those patients who were assessed for the same laboratory features at the end of summer. Demographic variables including age, sex, ethnicity, height and weight were recorded on a standard case report form for all patients. All of the participants were questioned about their nutritional intake (Ca and vitamin D) and physical activity (hours per week and time engaged in outdoor activities). The questionnaires included an assessment of Ca and vitamin D intake (dietary and supplements). Daily acidic beverage consumption was also assessed. The outdoor physical activity and dressing styles for female patients were determined as normal or covered completely with traditional clothing. Daily sun exposure and sunscreen usage were evaluated in patients. The two groups were compared in terms of demographic, clinical and laboratory characteristics.

\section{Laboratory Investigations}

Blood samples were obtained from 44 adolescents at the end of summer and 46 at the end of winter. Samples were assessed for $\mathrm{Ca}^{++}$phosphorus (P), magnesium (Mg), PTH, ALP and 25-OHD concentrations. Serum Ca, P and ALP were measured spectrophotometrically. Total 25-OHD levels in the sera were measured by a chemiluminescence immunoassay method (Diasorin Inc, Stillwater, MN). This assay uses an antibody that is able to detect both forms of 25-OHD (D2 and D3). The normal range for PTH is $10-55 \mathrm{pg} / \mathrm{mL}$.

The patients were divided into 3 diagnostic categories according to their serum 25-OHD concentrations: Vitamin D insufficiency $15-20 \mathrm{ng} / \mathrm{mL}$; Vitamin D deficiency $15 \mathrm{ng} /$ $\mathrm{mL}$ or less; severe Vitamin D deficiency $8 \mathrm{ng} / \mathrm{mL}$ or less. The definition of Vitamin D deficiency; serum 25-OHD levels of $15 \mathrm{ng} / \mathrm{mL}$ or less had elevated serum PTH concentrations. Subclinical vitamin $D$ deficiency is characterized by an inadequate vitamin D level without overt specific signs and symptoms referred to altered mineral homeostasis.

\section{Statistical Analysis}

Statistical analyses were performed using IBM SPSS version 21.0 for personal computers (Chicago, IL, USA). The subjects were divided into two groups: the first group was those patients who were assessed for vitamin D levels and the other laboratory measurements at the end of winter $(n=46)$, the second group was those patients who were assessed for the same laboratory features at the end of 
summer $(n=44)$. The Shapiro-Wilk test was used to check the normality assumption of the continuous variables. $\chi^{2}$ test was used to compare categorical data. In cases of nonnormally distributed data, the Mann-Whitney $U$ test was used to determine whether the difference between the two groups was statistically significant. The Student's t-test was used for continuous variables that were normally distributed. For correlation, the Pearson correlation analysis was utilized. A value of $p<0.05$ was considered as statistically significant.

\section{Results}

In this study, 90 adolescents $\leq 18$ years of age who were admitted with various reasons to the outpatient clinics were accepted into the study. The median age of all patients in the study was $11 \pm 4$ years. The subjects were divided into two groups; the first group consisted of those patients who were assessed for vitamin $D$ levels and the other laboratory measurements at the end of winter $(n=46)$, the second group consisted of those patients who were assessed for the same laboratory features at the end of summer $(n=44)$. The two groups were compared in terms of demographic, clinical and laboratory characteristics.

Table I shows the demographic characteristics and laboratory results of adolescents who were evaluated at the end of winter and summer. The mean age of the participants of the winter group was $12.5 \pm 2.6$ years and of the summer group $11.3 \pm 2.1$ years. When the two groups were compared in terms of age, there was a significant statistical difference $(p<0.05)$.

Of the winter and summer groups, $45.7 \%$ and $45.5 \%$ were male, respectively. There was no significant difference in gender $(p>0.05)$. The median vitamin $D$ levels were as follows; for the end of the winter period; $28.1 \pm 16.9 \mathrm{nmol} / \mathrm{L}$ and for the end of the summer period; $25.4 \pm 19.2 \mathrm{nmol} / \mathrm{L}$. This parameter is not statistically significant for the groups $(p=0.288)$. The Vitamin D deficiency percentage of the study group for the end of the winter period was $60.8 \%$ and for the end of the summer period, it was $15.9 \%$ but this was not significantly statistically significant. The Vitamin D

Table I. The demographic characteristics and laboratory results of the adolescents

\begin{tabular}{|c|c|c|c|}
\hline & End of Winter group $(n=46)$ & End of Summer group $n=44$ ) & $p$ value \\
\hline \multicolumn{4}{|l|}{ Demographic data } \\
\hline Age, years (mean $\pm S D$ ) & $12.5 \pm 2.6$ & $11.3 \pm 2.1$ & $0.016^{*}$ \\
\hline $\begin{array}{l}\text { Gender } \\
\text { Male, n (\%) } \\
\text { Female, n (\%) }\end{array}$ & $\begin{array}{l}21(45.7) \\
25(54.3) \\
\end{array}$ & $\begin{array}{l}20(45.5) \\
24(55.5) \\
\end{array}$ & $0.985^{\dagger}$ \\
\hline Exposure to sunlight, minute (mean \pm SD) & $96.7 \pm 69.5$ & $100.6 \pm 94$ & $0.622^{*}$ \\
\hline $\begin{array}{l}\text { Traditional clothing (mother), } \mathbf{n}(\%) \\
\text { Yes } \\
\text { No }\end{array}$ & $\begin{array}{l}26(56.5) \\
20(43.5) \\
\end{array}$ & $\begin{array}{l}20(45.5) \\
24(54.5) \\
\end{array}$ & $0.399+$ \\
\hline $\begin{array}{l}\text { Acidic beverage consumption, } \mathbf{n}(\%) \\
\text { Yes } \\
\text { No }\end{array}$ & $\begin{array}{l}29(63.1) \\
17(36.9)\end{array}$ & $\begin{array}{l}28(63.6) \\
16(36.3)\end{array}$ & $1.0 \ddagger$ \\
\hline $\begin{array}{l}\text { Sunscreen use, } \mathbf{n}(\%) \\
\text { Yes } \\
\text { No }\end{array}$ & $\begin{array}{l}7(15.3) \\
39(84.7)\end{array}$ & $\begin{array}{l}7(15.9) \\
37(84.1)\end{array}$ & $0.928^{\dagger}$ \\
\hline Daily physical activity (h/week) (mean \pm SD) & $1.7 \pm 1.3$ & $2.5 \pm 2$ & $0.082^{*}$ \\
\hline \multicolumn{4}{|l|}{ Laboratory Findings } \\
\hline $\mathrm{Ca}(\mathrm{mg} / \mathrm{dL})$, median, $(\mathrm{IR})$ & $9.8(0.6)$ & $9.9(0.5)$ & $0.119^{*}$ \\
\hline $\mathrm{P}(\mathrm{mg} / \mathrm{dL})$, median, $(\mathrm{IR})$ & $4.6(0.9)$ & $4.9(0.5)$ & $0.149^{*}$ \\
\hline $\mathrm{Mg}(\mathrm{mg} / \mathrm{dL})$, median, (IR) & $2.1(0.3)$ & $2.1(0.2)$ & $0.461^{*}$ \\
\hline ALP (U/L), median, (IR) & $200(142)$ & $199(98)$ & $0.386^{*}$ \\
\hline PTH (pg/mL), median, (IR) & $42.4(24.5)$ & $43.2(19.5)$ & $0.283^{*}$ \\
\hline Vitamin D level (nmol/L), median, (IR) & $28.1 \pm 16.9$ & $25.4 \pm 19.2$ & $0.288^{*}$ \\
\hline Vitamin D insufficiency, n (\%) & $41(93.2)$ & $18(39.2)$ & $0.082^{\dagger}$ \\
\hline Vitamin D deficiency, n (\%) & $28(60.8)$ & $7(15.9)$ & $0.387^{\dagger}$ \\
\hline
\end{tabular}

*Mann-Whitney U test; †chi-square test; $¥$ Fisher's exact test; SD: Standard deviation, Ca: Calcium, IR: Interquartile range, P: Phosphorus, Mg: Magnesium, ALP: Alkaline phosphatase, PTH: Parathyroid hormone 
insufficiency percentage of the summer group was higher than the winter group $(93.2 \%$ vs. $39.2 \%, p>0.05)$. The frequency of vitamin D deficiency was significantly higher in girls $(10.2 \%)$ than in boys at the end of the summer group $(p=0.042$, data not shown). However, the end of the winter group had no difference in terms of gender. There were also no differences between the groups in terms of laboratory findings including $\mathrm{Ca}, \mathrm{Mg}$ and the other bone parameters.

The mean sun exposure time of the two groups was similar. Traditional clothing (covering the entire body except the face and hands) was very rare for both study groups (3.5\% and $5.9 \%$, data not shown). However, almost half of the subjects' mothers used the traditional clothing. The daily use of Ca was determined to be mostly low in both groups; for summer, it was $3.7 \%$ and $4.2 \%$ (not shown) for the winter group. When the groups were analyzed for acidic beverage consumption, its frequency was similarly high in both groups (63.6\% for summer and $63.1 \%$ for winter). Sunscreen use was slightly higher in the summer group than in the winter one (15.9\% vs. 15.3\%). The mean daily physical activity of both groups was similar (for summer $1.7 \mathrm{hrs}$ and for winter $2.5 \mathrm{hrs}$ daily, $p=0.082$ ).

\section{Discussion}

In this study, we evaluated whether there is a significant difference of vitamin D status in terms of a seasonal pattern and whether there is an association between several other factors and vitamin D deficiency. The vitamin D in our populations of adolescents showed a high percentage (34.4\%) in Izmir, Turkey. The relative prevalence of vitamin $D$ deficiency, insufficiency and sufficiency varies in different studies according to the different cut-offs for specifying the optimal vitamin D status. It is reported that the prevalence of both vitamin $D$ deficiency and insufficiency increased in $10-15$ years from 22\% to 41\% between 1988 and 2004, with an increase in the prevalence of subclinical vitamin $D$ deficiency from $53 \%$ to $71 \%$ in United States of America (USA) (11). A systematic review (168.000 participants) reported that 88.1\% of the participants had mean $25-\mathrm{OHD}$ values below $75 \mathrm{nmol} / \mathrm{L}$, $37.3 \%$ had mean values below $50 \mathrm{nmol} / \mathrm{L}$ and $6.7 \%$ had mean values below $25 \mathrm{nmol} / \mathrm{L}$ (12). Cashman et al. (13) stated that $13.0 \%$ of the 55.844 European individuals had serum 25-OHD concentrations $<30 \mathrm{nmol} / \mathrm{L}$ on average in the year, with $17.7 \%$ and $8.3 \%$ in those sampled during the extended winter (October-March) and summer (April-November) periods, respectively. Another study conducted by Karagüzel et al. (14) reported that the prevalence of vitamin D deficiency was $93 \%$ during spring and $71 \%$ during autumn in 746 healthy students aged between 11 and 18 years. They also declared that the age, sex and Ca level were found to be independent predictors for vitamin $\mathrm{D}$ deficiency and that vitamin $\mathrm{D}$ deficiency was higher in girls than boys (87\%, 78\%, respectively). In Beirut, a study reported that vitamin D deficiency was $65 \%$ in the winter season and $40 \%$ at the end of the summer (15). In our study, the vitamin D level of the winter group was $28.1 \mathrm{nmol} / \mathrm{L}$ and the summer group was $25.4 \mathrm{nmol} / \mathrm{L}$ and the winter group was $60.8 \%$, there was no statistical significance in both groups. However, vitamin D insufficiency at the end of winter was prominently higher than the summer group. We could not find any relationship between the seasonal pattern and the other factors. Moreover, the girls who wore traditional dress covering the entire body had concentrations not lower than $15 \mathrm{nmol} / \mathrm{L}$. In our population, although there was a high frequency of vitamin D deficiency, the PTH was within the normal range in both groups.

During the Industrial Revolution, vitamin D deficiency appeared in epidemic form in temperate zones where the pollution from factories blocked the sun's ultraviolet rays. Thus, vitamin D deficiency is probably the first childhood and adolescent disease caused by environmental pollution. In terms of the time of exposure to sunlight, as expected, the end of our summer group had higher levels than those at the end of our winter group, but this was not statistically significant. In winter time, due to the fact that there is inadequate sunlight, increased pollution and the factor of being $32^{\circ} \mathrm{N}$, it leads to inadequate production of vitamin $\mathrm{D}$ in the skin, vitamin D levels are very low during winter (16).

The link between vitamin $D$ deficiency and rickets is well understood. However, subclinical vitamin D deficiency may also be detrimental to bone health in childhood. Its effects on bone mineralization have the potential to result in lower peak bone mass being attained, which could in turn contribute to increased fracture risk in both childhood and older adult life. Unfortunately, natural foods containing vitamin $D$ are limited. To protect bone health in children and adolescents and for public health policy, the aim should be to ensure sufficient vitamin $D$ intakes in the majority of the world population (12). In Turkey, the Ministry of Health started free vitamin D supplementation for every infant to protect against deficiency and rickets. However, there is no national vitamin $D$ fortification program in children and adolescents with a vitamin A deficiency who have a tendency to skeletal disorders. The Endocrine Society clinical practice guideline recommends that infants and children aged from 0-1 year require at least $400 \mathrm{IU} / \mathrm{d}(\mathrm{IU}=25 \mathrm{ng})$ of vitamin $\mathrm{D}$ and children 1 year and older require at least $600 \mathrm{lU} / \mathrm{d}$ (17). Vitamin D deficiency is common in our rural and urban areas among adolescents so we believe that they need vitamin D supplementation regularly.

Increased PTH levels associated with low vitamin D levels have been known for a long time. A study reported that there is a negative correlation between 25-OHD and PTH. It has also been reported that an increase in PTH level occurs at $25-\mathrm{OHD}$ levels between 25 and $82.5 \mathrm{ng} / \mathrm{mL}$ (7,34-37) and serum PTH levels start to rise as 25-OHD levels decline below 
$35.8 \mathrm{nmol} / \mathrm{L}$ (14). In our study, we could not find a correlation between PTH and vitamin D levels in the two groups via Pearson correlation analysis.

The determination of a winter-time subclinical vitamin $D$ insufficiency of $39.2 \%$ is in agreement with the findings of another study from Turkey (18). Our healthy adolescent population findings show a problem even in the sunny climate of Turkey. The relationships between vitamin $D$ and $\mathrm{Ca}$ intakes of adolescents indicates that an adequate daily $\mathrm{Ca}$ intake is important and provides protection to our adolescents from insufficiency. Akman et al. (19) evaluated 849 healthy children between 1-16 years and they found that the prevalence of vitamin $D$ deficiency $(<20 \mathrm{ng} / \mathrm{mL})$ was $8 \%$ and that of vitamin D insufficiency was $25.5 \%$ in the population investigated. Also, they reported that the average daily intake of Ca was especially low in the $>8$-year-old age group ( $<1300 \mathrm{mg} /$ day) similar to our study. In our current study, the daily Ca intake was low in $60.3 \%$ of all patients and $63.3 \%$ consumed acidic beverages. Similar to our study, Akman et al. (19) revealed that the intake of Ca was found to be low, especially in school children and adolescents. Previous studies conducted in two urban areas of Turkey reported that the daily Ca intake was found to be very low ( $266 \mathrm{mg} /$ day) in adolescent girls (18).

There were no statistically significant differences in the laboratory results between the two groups. There were also no statistically significant correlations between serum vitamin D status and subjects' diet, periods of exposure to sunlight, the use of sunscreen, regular physical activities, traditional clothing of mothers or clothing style in our study.

There are several limitations of the present study. The major one is that the present study is focused on only 90 healthy adolescents, so the study sample population size was small. Another limitation is that the study was conducted in western Turkey; thus, our results are not necessarily true for the entire Turkish population and all geographical regions.

Our findings suggest that vitamin $D$ deficiency and insufficiency is an important problem among apparently healthy Turkish adolescents especially at the end of the winter period and especially for females. We recommend supplemental vitamin D intake and outdoor activities for sunlight exposure to improve the vitamin $D$ status of adolescents. We also suggest that vitamin $D$ supplementation should be necessary for adolescents, and the guidelines should be modified for children and adolescents in terms of adequate vitamin $D$ intake in Turkey.

\section{Ethics}

Ethics Committee Approval: Retrospective study.

Informed Consent: Informed consent was obtained from the parents or guardians of all eligible children.

Peer-review: Externally and internally peer-reviewed.

\section{Authorship Contributions}

Concept: G.G., Ş.G., A.A., Z.K., G.K., Design: Ş.G., Data Collection: G.G., S..G., A.A., Analysis or Interpretation: G.K., A.A., Z.K., Literature Search: Z.K., G.K., Writing: Ş.G. Conflict of Interest: No conflict of interest was declared by the authors.

Financial Disclosure: The authors declared that this study received no financial support.

\section{References}

1. Misra M, Pacaud D, Petryk A, Collett-Solberg PF, Kappy M; Drug and Therapeutics Committee of the Lawson Wilkins Pediatric Endocrine Society. Vitamin D deficiency in children and its management: review of current knowledge and recommendations. Pediatrics 2008;122:398-417.

2. Hollis BW. Circulating 25-hydroxyvitamin D levels indicative of vitamin D sufficiency: implications for establishing a new effective dietary intake recommendation for vitamin D. I Nutr 2005;135:317-22.

3. Callaghan AL, Moy RJ, Booth IW, Debelle G, Shaw NJ et al. Incidence of symptomatic vitamin D deficiency. Arch Dis Child 2006;91:606-7.

4. Gordon CM, DePeter KC, Feldman HA, Grace E, Emans S) et al. Prevalence of vitamin $D$ deficiency among healthy adolescents. Arch Pediatr Adolesc Med 2004;158:531-7.

5. Munns CF, Shaw N, Kiely $M$, et al. Global Consensus Recommendations on Prevention and Management of Nutritional Rickets. J Clin Endocrinol Metab 2016;101:394-415.

6. Holick MF, Binkley NC, Bischoff-Ferrari HA, et al. Endocrine Society. Evaluation, treatment, and prevention of vitamin $D$ deficiency: an Endocrine Society clinical practice guideline. ) Clin Endocrinol Metab 2011;96:1911-30.

7. Mansbach JM, Ginde AA, Camargo CA Jr et al. Serum 25-hydroxyvitamin D levels among US children aged 1 to 11 years: do children need more vitamin D? Pediatrics 2009;124:1404-10.

8. Saintonge $S$, Bang $H$, Gerber LM et al. Implications of a new definition of vitamin $D$ deficiency in a multiracial us adolescent population: the National Health and Nutrition Examination Survey III. Pediatrics 2009;123:797-803.

9. Manios Y, Moschonis G, Hulshof T et al. Prevalence of vitamin $D$ deficiency and insufficiency among schoolchildrenin Greece: the role of sex, degree of urbanisation and seasonality. Br J Nutr 2017; $118: 550-8$.

10. Gonzalez-Gross M, Valtuena ), Breidenassel C, et al. Vitamin D status among adolescents in Europe: the Healthy Lifestyle in Europe by Nutrition in Adolescence study. Br ) Nutr 2012;107:75564.

11. Ginde AA, Liu MC, Camargo CA Jr. Demographic Differences and Trends of Vitamin D Insufficiency in the US Population, 1988-2004. Arch Intern Med 2009;169:626-32.

12. Hilger J, Friedel A, Herr R, et al. A systematic review of vitamin D status in populations worldwide. Br J Nutr 2014;111:23-45.

13. Cashman KD, Dowling KG, Skrabáková Z, et al. Vitamin D deficiency in Europe: pandemic? Am J Clin Nutr 2016;103:103344.

14. Karagüzel G, Dilber B, Çan G, Ökten A, Değer O, Holick MF. Seasonal Vitamin D Status of Healthy Schoolchildren and Predictors of Low Vitamin D Status. I Pediatr Gastroenterol Nutr 2014;58:654-60. 
15. El-Hajj Fuleihan G, Nabulsi M, Choucair M, et al. Hypovitaminosis D in healthy schoolchildren. Pediatrics 2001;107:53.

16. Webb AR, Kline L, Holick MF. Influence of season and latitude on the cutaneous synthesis of vitamin D3: exposure to winter sunlight in Boston and Edmonton will not promote vitamin D3 synthesis in human skin. J Clin Endocrinol Metab 1988;67:373-8.

17. Holick MF, Binkley NC, Bischoff-Ferrari HA et al. Evaluation, Treatment, and Prevention of Vitamin D Deficiency: an Endocrine Society Clinical Practice Guideline. I Clin Endocrinol Metab 2011;96:1911-30.
18. Olmez D, Bober E, Buyukgebiz A, Cimrin D. The frequency of vitamin $D$ insufficiency in healthy female adolescents. Acta Pædiatrica 2006;95:1266-9.

19. Akman $A O$, Tumer $L$, Hasanoglu A, İlhan $M$, Çaycı B et al. Frequency of vitamin $D$ insufficiency in healthy children between 1 and 16 years of age in Turkey. Pediatr Int 2011;53:96873. 